\title{
Abnormal yawning in stroke patients: the role of brain thermoregulation
}

\author{
Andrew C. Gallup* \\ Psychology Department, State University of New York at Oneonta, Oneonta, NY, USA \\ *Correspondence: a.c.gallup@gmail.com
}

Edited by:

André Diedrich, Vanderbilt University, USA

Reviewed by:

Christopher J. Madden, Oregon Health \& Science University, USA

Keywords: yawning, stroke, brain temperature, thermoregulation, excessive yawning

\section{A commentary on}

Insular and caudate lesions release abnormal yawning in stroke patients by Krestel, H., Weisstanner, C., Hess, C. W., Bassetti, C. L., Nirkko, A., and Wiest, R. (2013). Brain Struct. Funct. doi: 10.1007/ s00429-013-0684-6. [Epub ahead of print].

Krestel et al. (2013) recently investigated the potential contributing factors associated with abnormal yawning (defined as $\geq 3$ yawns/ $15 \mathrm{~min}$ ) in 10 patients with acute anterior circulation stroke. Though frequent yawning had previously been observed in stroke patients (Cattaneo et al., 2006; Singer et al., 2007), this study attempted to assess the influence of specific physiologic and lesion topographic variables contributing to this association. All patient parameters were taken within $1 \mathrm{~h}$ after admission and emergency nurses recorded a single axillary body temperature with a digital thermometer (Krestel, personal communication). Using MRI lesion maps, and reportedly finding no associations between various physiologic measures, including blood oxygen saturation, glucose, body temperature, blood pressure, and heart rate, the authors concluded that ischemic lesions in the posterior insula and caudate nucleus might facilitate high frequency yawning in stroke patients. While this report improves our neurological understanding regarding the association between frequent yawning in stroke patients, limitations in the analysis and interplay of temperature need to be addressed.

Yawning is characterized by a powerful gaping of the jaw with inspiration, a brief period of peak muscle contraction, and a passive closure of the jaw with shorter expiration (Barbizet, 1958). The localized circulatory changes resulting from this action pattern have led researchers to hypothesize that yawns may function to cool the brain (Gallup and Gallup, 2007). For example, yawns produce increases in blood flow to the skull and enhanced venous return (Bhangoo, 1974), while the deep inhalation during yawning can modify the temperature of venous blood draining from the nasal and oral orifices into the cavernous sinus, which surrounds the internal carotid artery (Zenker and Kubik, 1996). Together, these processes act like a radiator removing hyperthermic blood from brain while introducing cooler arterial blood to the brain. Moreover, the flexing of the musculature during yawning may encourage the evaporation of the sinus mucosa (see Gallup and Hack, 2011). Research supporting the brain cooling hypothesis has accumulated over the past 5 years, including evidence for predicted brain and body temperature fluctuations surrounding yawning events, indirect manipulations of brain temperature causing a reduction in yawn frequency, and an altered expression of yawning which appears to be driven by ambient temperature manipulation/variation (reviewed by Gallup and Eldakar, 2013). For example, by directly monitoring continuous changes in prelimbic cortex temperature of rats it was shown that yawning is preceded by intermittent and rapid increases in brain temperature (i.e., $\sim 0.1^{\circ} \mathrm{C} / \mathrm{min}$ ), and that following the completion of a yawn the slope of the temperature change reverses and quickly returns to baseline (Shoup-Knox et al., 2010).

While the breadth of physiologic measures taken by Krestel et al. (2013) is laudable, a single measure of axillary temperature taken long after the onset of the yawning episode is inadequate for assessing this relationship. Since distinct brain temperature changes in rats occur before and after single yawns on a rather short temporal scale; i.e., 60-90 s (ShoupKnox et al., 2010), and isolated bouts of excessive yawning in humans have been shown to reduce skull temperature by as much as $0.4^{\circ} \mathrm{C}$ (Gallup and Gallup, 2010), it remains possible that the pathological yawning experienced by these patients was accompanied by recurrent changes in temperature that were never recorded. Furthermore, temperature measures taken from the skull (e.g., oral, tympanic, forehead) would be more informative since the motor pattern of yawning and the associated circulatory changes are localized to this area. That said, even these measurements could miss important temperature fluctuations confined to particular brain regions.

The use of MRI lesion maps to establish a relationship between ischemic lesions in the posterior insula and caudate nucleus and the duration of abnormal yawning is certainly of great importance (Krestel et al., 2013). At this point, however, it is premature to declare that there was "no evidence of other potential causes" related to abnormal yawning in these patients. To the contrary, frequent or abnormal yawning in stroke patients may be a consequence of thermoregulatory dysfunction associated with the brain injury 
(Gallup and Gallup, 2008). Given the close temporal association between yawning and changes in brain/skull temperature, future research monitoring patients with abnormal or excessive yawning bouts should take continuous temperature measures from areas proximate to the cranium in order to properly assess this relationship.

\section{REFERENCES}

Barbizet, J. (1958). Yawning. J. Neurol. Neurosurg. Psychiatry 21, 203-209. doi: 10.1136/jnnp.21.3.203

Bhangoo, K. S. (1974). Why the yawn? N Engl. J. Med. 290,1440

Cattaneo, L., Cucurachi, L., Chierici, E., and Pavesi, G. (2006). Pathological yawning as a presenting symptom of brain stem ischaemia in two patients. J. Neurol. Neurosurg. Psychiatry 77, 98-100. doi: 10.1136/jnnp.2005.075267

Gallup, A. C., and Eldakar, O. T. (2013). The thermoregulatory theory of yawning: what we know from 5 years of research. Front. Neurosci. 6:188. doi: 10.3389/fnins.2012.00188

Gallup, A. C., and Gallup, G. G. Jr. (2007). Yawning as a brain cooling mechanism: nasal breathing and forehead cooling diminish the incidence of contagious yawning. Evol. Psychol. 5, 92-101.

Gallup, A. C., and Gallup, G. G. Jr. (2008). Yawning and thermoregulation. Physiol. Behav. 95, 10-16. doi: 10.1016/j.physbeh.2008.05.003

Gallup, A. C., and Hack, G. D. (2011). Paranasal sinuses and selective brain cooling in humans: a ventilation system activated by yawning? Med. Hypotheses 77, 970-973. doi: 10.1016/j.mehy.2011.08.022

Gallup, G. G. Jr., and Gallup, A. C. (2010). Yawning and thermoregulation: two case histories of chronic, debilitating bouts of yawning. Sleep Breath. 14, 157-159. doi: 10.1007/s11325009-0287-x

Krestel, H., Weisstanner, C., Hess, C. W., Bassetti, C. L., Nirkko, A., and Wiest, R. (2013). Insular and caudate lesions release abnormal yawning in stroke patients. Brain Struct. Funct. doi: 10.1007/s00429013-0684-6. [Epub ahead of print].

Shoup-Knox, M. L., Gallup, A. C., Gallup, G. G. Jr., and McNay, E. C. (2010). Yawning and stretching predict brain temperature changes in rats: support for the thermoregulatory hypothesis. Front. Evol. Neurosci. 2:108. doi: 10.3389/fnevo.2010.00108

Singer, O. C., Humpich, M. C., Lanfermann, H., and Neumann-Haefelin, T. (2007). Yawning in acute anterior circulation stroke. J. Neurol.
Neurosurg. Psychiatry 78, 1253-1254. doi: 10.1136/jnnp.2006.111906

Zenker, W., and Kubik, S. (1996). Brain cooling in humans - anatomical considerations. Anat. Embryol. 193, 1-13. doi: 10.1007/BF001 86829

Conflict of Interest Statement: The author declares that the research was conducted in the absence of any commercial or financial relationships that could be construed as a potential conflict of interest.

Received: 19 June 2014; accepted: 02 September 2014; published online: 17 September 2014.

Citation: Gallup AC (2014) Abnormal yawning in stroke patients: the role of brain thermoregulation. Front. Neurosci. 8:300. doi: 10.3389/fnins.2014.00300 This article was submitted to Autonomic Neuroscience, a section of the journal Frontiers in Neuroscience. Copyright () 2014 Gallup. This is an open-access article distributed under the terms of the Creative Commons Attribution License (CC BY). The use, distribution or reproduction in other forums is permitted, provided the original author(s) or licensor are credited and that the original publication in this journal is cited, in accordance with accepted academic practice. No use, distribution or reproduction is permitted which does not comply with these terms. 